\title{
ESTUDO COMPARADO DO DESENVOLVIMENTO DE DOIS MORFOTIPOS LARVAIS DE COCHLIOMYIA MACELLARIA (FABRICIUS) (DIPTERA, CALLIPHORIDAE) $^{1}$
}

\author{
Sandra L. Cunha-e-Silva ${ }^{2}$ \\ Eliane M.V. Milward-de-Azevedo ${ }^{3}$
}

\begin{abstract}
COMPARATIVE STUDY OF THE DEVELOPMENT OFTWO LARVAE MORPHOTYPES OF COCHLIOMYIA MACELLARIA (FABRICIUS) (DIPTERA, CALLIPHORIDAE). The possible dissimilitudes relating to the duration of the egg incubation period and larval stage of Cochliomyia macellaria (Fab., 1775)from offsprings of females from larvae with and without pigmentation on Malpighi tubules, morphotype 1 and 2, respectively, was questioned. The experiment was conducted in climatized chamber regulated at $30^{\circ} \mathrm{C}, 65 \pm 10 \% \mathrm{RH}$ and 14 hour photophase. No significant difference was observed on average duration of first and second larval instars between the two morphotypes, taking into account not only the conventional interpretation for the reading of different development phases of the larval stages (morphotype 1: 11.0 and 11.9 hours and morphotype 2: 11.7 and 12.7 hours for first and second instars, respectively), but also the reading made through the interpretation preconized by Snodgrass \& Hinton (morphotype 1: 10.3 and 9.6 hours and morphotype 2: 9.8 and 10.8 hours for the first and second instars, respectively). The incubation period was significantly longer for eggs posited by females from non-pigmented larvae. KEY WORDS. Secondary screwworm; blow fly; ontogeny, carrion-eating dipterous, necrophagous flies
\end{abstract}

A drástica redução de populações de Cochliomyia macellaria (Fabricius, 1775) em função da significativa pressão sofrida pela competição com larvas de Chrysomya spp. foi relatada por GUIMARÃES et al. (1978 e 1979), FERREIRA (1983) e BAUMGARTNER \& GREENBERG (1985). Entretanto, o desenvolvimento de linhagens naturalmente selecionadas de $C$. macellaria que incorporem estratégias para enfrentar este processo competitivo é uma hipótese que não pode ser descartada. Recentemente, LIU \& GREENBERG (1989) relataram qua as larvas de terceiro ínstar desta espécie são facilmente caracterizadas macroscopicamente por apresentarem túbulos de Malpighi densamente pigmentados. Esta pigmentação foi revelada também por CUNHA-E-SILVA et al. (no prelo). Em criações em nosso laboratório, em duas

1) Pesquisa desenvolvida com auxílio do CNPq.

2) Departamento de Estudos Básicos e Instrumentais, Universidade Estadual do Sudoeste da Bahia, 45700-000 Itapetinga, Bahia, Brasil.

3) Departamento de Biologia Animal, Universidade Federal Rural do Rio de Janeiro, 23851-970 Itaguaí, Rio de Janeiro, Brasil. Bolsista do CNPq. 
gerações consecutivas e utilizando-se massas de ovos originárias de um mesmo grupo de fêmeas, esta espécie apresentou larvas com e sem pigmentação no sistema excretor. Questionou-se assim, as possíveis dissimilaridades biométricas entre esses dois grupos de larvas. Considerando-se oportunamente, as duas interpretações relativas à subdivisão do estágio larval em ínstares, através da leitura feita pelo método convencional e o preconizado por Snodgrass \& Hinton (HINTON \& MACKERRAS, 1970), procurou-se avaliar o período de incubação dos ovos e a duração média dos ínstares larvais dos dois morfotipos, sob condições controladas.

\section{MATERIAL E MÉTODOS}

Os experimentos foram conduzidos em câmaras climatizadas reguladas à $65 \pm 10 \%$ de UR e 14 horas de fotofase. As massas de ovos de C. macellaria utilizadas neste estudo, originaram-se de lotes de adultos provenientes de colônia mantida no laboratório (Geração 10-12), de acordo com a metodologia preconizada por CUNHA-E-SILVA (1990). Estes adultos eram oriundos de dois morfotipos larvais, denominados de morfotipo $1 \mathrm{e} 2$. As larvas do morfotipo 1 apresentavam, in vivo, uma intensa e visível pigmentação dos túbulos de Malpighi (CUNHA-E-SILVA et al., no prelo), distinguindo-se das larvas do morfotipo 2 , sem pigmentação aparente. $\mathrm{O}$ estoque que deu origem aos lotes experimentais, foi mantido sob rígido controle de qualidade (CUNHA-E-SILVA, 1990) e não houve reintrodução de insetos nativos durante a sua manutenção. Fêmeas nulíparas acasaladas e oriundas das duas diferentes amostras, com 11 dias de idade, foram estimuladas a ovipositar ao introduzir-se, nas gaiolas, carne eqüina putrefata. Esta etapa pré-experimental foi conduzida a $27^{\circ} \mathrm{C}$. Após a oviposição, as massas de ovos foram pesadas, separadas em quatro parcelas/tratamento $(0,04 \mathrm{~g} /$ parcela $)$, colocadas em placas de Petri e forradas com papel filtro umedecido com água destilada e incubadas a $30^{\circ} \mathrm{C}$.

Após a eclosão, os lotes de larvas foram transferidos para recipientes contendo $250 \mathrm{~g}$ de dieta e mantidos à $30^{\circ} \mathrm{C}$. A dieta era constituída por carne eqüina putrefata (carne fresca descongelada e, em seguida mantida, durante 11 dias, em refrigerador); antes de sua utilização, este substrato era aquecido em estufa regulada a $30^{\circ} \mathrm{C}$, por um período de duas horas. Os recipientes plásticos $(7,5 \mathrm{~cm}$ de altura $\times 9,0 \mathrm{~cm}$ de diâmetro) relativos às diferentes parcelas experimentais, foram colocados dentro de vasilhas plásticas $(9 \mathrm{~cm}$ de altura $\times 14 \mathrm{~cm}$ de diâmetro), contendo vermiculita para servir como substrato para as larvas maduras, após o seu abandono espontâneo da dieta.

Foi coletada uma amostra de 10 larvas /repetição/tratamento, visando o reconhecimento das diferentes fases de desenvolvimento. Até 52 horas pósoviposição, as observações biológicas foram realizadas em intervalos de duas horas; após este período, em intervalos de 12 horas. Estas larvas eram imediatamente sacrificadas em líquido de San Jean aquecido à $60^{\circ} \mathrm{C}$, sendo fixadas nesta mesma substância para posterior análise e determinação da fase de desenvolvimento. Os ínstares larvais foram caracterizados de acordo com o 
número de aberturas espiraculares e a presença ou não de espiráculos anteriores, segundo KNIPLING (1939). Para determinar um ínstar do seguinte, foram considerados os métodos convencional e o preconizado por Snodgrass \& Hinton. No primeiro, as diferentes fases de crescimento e morfogênese (ínstares) são delimitados através da perda da exúvia, após o processo de ecdise; no segundo, são delimitadas através das apólises (HINTON \& MACKERRAS, 1970).

Os dados experimentais foram comparados pelo teste de Tukey, ao nível de $5 \%$ de probabilidade.

\section{RESULTADOS E DISCUSSÃO}

A duração média do primeiro e do segundo ínstar larval de C. macellaria e pertencentes aos morfotipos 1 e 2 , analisados independentemente pelo método convencional e o preconizado por Snodgrass \& Hinton, não diferiu significativamente; por outro lado, o período de incubação variou, apresentando-se mais prolongado na amostra relativa ao morfotipo 2 (Tab. I).

Tabela I. Período de incubação, duração do primeiro e segundo ínstar larval e período de ovo a pré-pupa de dois morfotipos de Cochliomyia macellaria em relação ao método que delimita os ínstares $\left(30^{\circ} \mathrm{C}, 65 \pm 10 \%\right.$ de ur e $14 \mathrm{~h}$ de fotofase). Itaguaí, RJ.

\begin{tabular}{|c|c|c|c|c|c|}
\hline \multirow[t]{2}{*}{ MORFOTIPOS } & \multirow[t]{2}{*}{ MÉTODOS } & \multirow{2}{*}{$\begin{array}{l}\text { PERÍODO DE } \\
\text { INCUBAÇÁO } \\
\text { (b) } \\
\bar{x} \pm s \bar{x}\end{array}$} & \multicolumn{2}{|c|}{ DURAÇĀO DOS ÍNSTARES } & \multirow{2}{*}{$\begin{array}{l}\text { PERÍODO DE } \\
\text { OVO A } \\
\text { PRÉ-PUPA } \\
\text { (h) }\end{array}$} \\
\hline & & & $\bar{x} \pm s_{\bar{x}}$ & $\bar{x} \pm s_{\bar{x}}$ & \\
\hline $\mathrm{COM}^{*}$ & CONVENCIONAL & $12,4 \pm 0,3 \mathrm{a}$ & $11,0 \pm 0,4 \mathrm{a} \mathrm{b}$ & $11,9 \pm 0,5$ b & $100 \mathrm{a}$ \\
\hline $\mathrm{COM}$ & SNODGRASS-HINTON & $12,4 \pm 0,3 \mathrm{a}$ & $10,3 \pm 0,5$ a & $9,6 \pm 0,4 \mathrm{a}$ & $100 \mathrm{a}$ \\
\hline SEM ${ }^{* *}$ & CONVENCIONAL & $13,3 \pm 0,2 b$ & $11,7 \pm 0,6 \mathrm{~b}$ & $12,7 \pm 0,5 \mathrm{~b}$ & $104 \mathrm{~b}$ \\
\hline SEM & SNODGRASS-HINTON & $13,3 \pm 0,2 \mathrm{~b}$ & $9,8 \pm 0,5 \mathrm{a}$ & $10,8 \pm 0,4 \mathrm{a}$ & $104 \mathrm{~b}$ \\
\hline
\end{tabular}

* Larva com pigmentação aparente nos túbulos de Malpighi.

** Larva sem pigmentação aparente nos túbulos de Malpighi.

Não houve diferença relativa ao morfotipo 1, quando foram comparados os dois métodos (convencional e de Snodgrass \& Hinton); entretanto, este período diferiu significativamente ao analisar-se, sob a mesma ótica, o morfotipo 2. Também foi observada uma diferença acentuada na duração média de larvas de segundo ínstar, ao comparar-se os dois diferentes métodos de interpretação (Tab. I). O intervalo de variação relativo à duração do primeiro e segundo ínstar foi maior quando interpretado através do contexto convencional (Fig. 1). Na amostra relativa ao morfotipo 1 , a primeira larva farata de primeiro ínstar (método convencional) e de segundo ínstar (método de Snodgrass \& Hinton), foi detectada em 24 horas após a oviposição; em 36 horas, detectou-se a primeira larva farata do segundo ínstar (método convencional) e de terceiro ínstar 
(método de Snodgrass \& Hinton). A partir das 56 horas, todas as larvas já se encontravam no terceiro ínstar. As larvas do morfotipo 1 abandonaram o meio mais cedo (100 horas) do que as larvas do morfotipo 2 (104 horas) (Tab. I e Fig. 1).
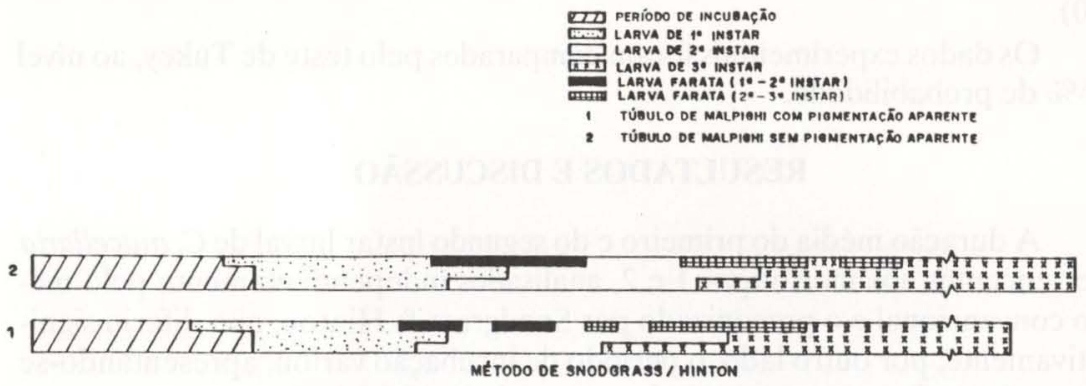

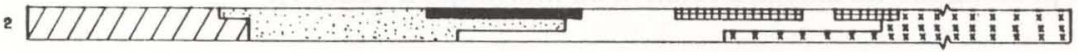

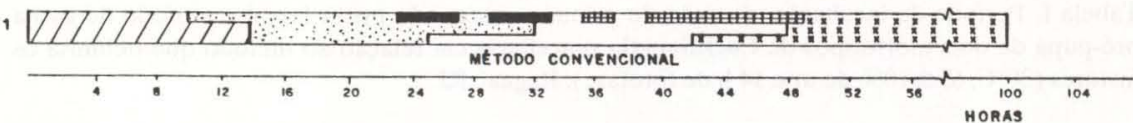

Figura 1. Período de incubação e duração do primeiro e segundo ínstar de dois morfotipos larvais de Cochliomyia macellaria, até o abandono espontâneo das larvas de terceiro ínstar da dieta, em relação ao método que delimita os ínstares $\left(30^{\circ} \mathrm{C}, 65 \pm 10 \%\right.$ de UR e $14 \mathrm{~h}$ de fotofase $)$. Itaguaí, RJ.

Durante 24 horas, a carne usada no experimento, apresentou contaminação por microorganismos e ficou com uma coloração esbranquiçada. Após este período, observou-se um aparente decréscimo deste quadro, paralelo a um aumento da liquefação da dieta. Às 38 horas após eclosão, não detectou-se mais a aparência de contaminação microbiana. STEWART (1934) citou o efeito benéfico de larvas de Phaenicia sericata (Meigen, 1826) no tratamento de osteomielite, pela eliminação do tecido necrosado e conseqüente desinfecção da ferida. Vários trabalhos citados por SINGH (1977), HANSKI (1987) e HAMMAK (1990), entre outros, têm discorrido sobre a asssociação de dípteros califorídeos e microorganismos.

As larvas mantiveram-se agregadas durante as primeiras 40 horas após a eclosão; à partir de então, apresentaram movimento aleatório e contínuo no meio. LAAKE et al. (1936), já haviam notado esse comportamento na espécie C. macellaria. STEWART (1934) reportou que larvas de moscas varejeiras, quando colocadas em meio xênico, se concentram em número relativamente grande em determinados locais. Estas observações permitem sugerir que o comportamento de agregação no início do desenvolvimento possa facilitar a utilização do alimento, seja pela ação do calor metabólico e/ou pela liberação de enzimas ou substâncias, associadas ou não a microorganismos, que atuam na 
degradação do alimento (HENSKI, 1987). WOLLELAN (1911) e HOBSON (1931), segundo STEWART (1934), demonstraram a presença de enzimas proteolíticas e lipolíticas no excreta de larvas varejeiras.

Recentemente, LIU \& GREENBERG (1989), ao revisarem a morfologia de algumas espécies de Calliphoridae, destacaram como característica diferencial para o reconhecimento in vivo de larvas de terceiro ínstar de $C$. macellaria a presença de pigmentação visível nos túbulos de Malpighi dos espécimens analisados. No presente experimento, algumas larvas (G12) oriundas de pais pertencentes ao morfotipo 2 e 26 horas após a eclosão, apresentaram pigmentação aparente; $100 \%$ da prole (G13) originada do morfotipo 2 apresentou os túbulos de Malpighi com intensa pigmentação. Estabeleceu-se, em seguida a este ensaio, uma nova colônia no laboratório, à partir de adultos nativos coletados na mesma área geográfica anteriormente amostrada, e sua manutenção foi acompanhada até a $14^{a}$ geração, sob as mesmas condições, na tentativa de detectar-se, novamente, o aparecimento dos dois morfotipos; entretanto, evidenciou-se apenas larvas do morfotipo 1. Torna-se, assim, necessária a criação monitorada (como inclusão de análises citogenéticas) de $C$. macellaria proviniente de diferentes regiões geográficas, para auxiliar a compreensão do evento em questão.

\section{REFERÊNCIAS BIBLIOGRÁFICAS}

BAUMGARTNER, D.L. \& B. GREENBERG. 1985. Distribution and medical ecology of the blow flies (Diptera: Calliphoridae) of Peru. Ann. Ent. Soc. Amer. 78 (5): 565-587.

CUNHA-E-SILVA, S.L. 1990. Aspectos da biologia de Cochliomyia macellaria (Fabricius) (Diptera, Calliphoridae), sob condições de laboratório. Tese de Mestrado, não publicada, Universidade Federal Rural do Rio de Janeiro, Rio de Janeiro, 90p.

CUNHA-E-SILVA, S.L.; A.C.V. SANTOS \& T. INADA. (no prelo). Observações de pigmentos nos túbulos de Malpighi em larvas de Cochliomyia macellaria (Fabr.) e C. hominivorax (Coq.) (Diptera, Callphoridae). An. Soc. Ent. Bras.

FERREIRA, M.J.M. 1983. Sinantropia de Calliphoridae (Diptera) em Goiânia, Goiás. Rev. Brasil. Biol. 43 (2): 199-210.

GUIMARÃES, J.H.; A.P. PRADO \& A.X. LINHARES. 1978. Three newly introduced blowfly species in southern Brazil (Diptera, Calliphoridae). Revta bras. Ent. 22: 53-60.

GUIMARÃES, J.H.; A.P. PRADO \& G.M. BURALLI. 1979. Dispersal and distribution of three newly introduced species of Chrysomya Robineau-Desvoidy in Brazil (Diptera, Calliphoridae). Revta bras. Ent. 23: 245-255.

HAMMACK, L. 1990. Protein feeding and oviposition effects on attraction of screwworm flies (Diptera, Calliphoridae) to host fluids. Ann. Ent. Soc. Amer. 83 (3): 97-102. 
HANSKY, I. 1987. Nutritional ecology of dung and carrion feeding insects. In: F. SLANSKY JR. \& J.G. RODRIGUES (ed.) Nutritional ecology if insects, mites, spiders and related Invertebrates. An: Overwiew, N.Y., 1016p.

HINTON, H.E. \& J.M. MACKERRAS. 1970. Reproduction and metamorphosis, p. 83-104. In: CSIRO (ed.) The insects of Australia. A testbook for students and research workers. Carlton, Melbourne University Press, XIII + 1029 .

KNIPLING, E.F. 1939. A key for blowfly larvae concerned in wound and cutaneos myiasis. Ann. Ent. Soc. Amer. 32: 376-383.

LAAKE, E.W.; E.C. CUSHING \& H.E. PARISH. 1936. Biology of the primary screwworm fly, Cochliomyia americana, and a comparison of it's stages with those of C. macellaria. USDA, Tech. Bull., Washington, 500: 24.

LIU, D. \& B. GREENBERG. 1989. Immature stages of flies of forensic importance. Ann. Ent. Soc. Amer. 83 (1): 80-93.

SING, P. 1977. Artificial diet for insects, mites and spiders. N.Y., Plenum Press, 594p.

STEWART, M.A. 1934. The role of Lucilia sericata Meig. larvae in osteomyelitis wounds. Ann. Trop. Med. Parasi. 28: 445-460.

Recebido em 03.II.1992; aceito em 03.V.1993. 